\title{
Influence of Causal Factors towards Internal Educational Quality Assurance of a University Course Tier
}

\author{
1 Wannapa Yaimak \& ${ }^{2}$ Senee Puangyanee
}

\begin{abstract}
This study investigated the various factors affecting the operational efficiency of the internal educational quality assurance at Rajamangala University of Technology. It particularly assessed the strategic management, transformational leadership, motivation, and operational efficiency of the internal quality assurance. It also tested the consistency of the causal model of factors affecting operational efficiency of internal educational quality assurance and the influence of strategic management, transformational leadership, and motivation on the internal educational quality assurance. Data collected from the 236 lecturers of the different courses from the nine (9) campuses of the university were analyzed using the path analysis. The results revealed that the respondents have high regards on the strategic management, transformational leadership, and motivation. The hypothesis testing showed that the causal model of factors was consistent with the empirical data. The strategic management and motivation directly affected operational efficiency of the internal educational quality assurance with statistical significance level of 0.05 and 0.01 , respectively. Meanwhile, transformational leadership affected the operational efficiency of internal educational quality assurance at statistically insignificant level. The results of the study would be useful for the enhancement of the internal quality assurance practices of universities in Thailand.
\end{abstract}

Keywords:

strategic management, transformational leadership, operational efficiency, quality assurance, higher education

Suggested Citation: Wannapa Yaimak \& Senee Puangyanee (2021). Influence of Causal Factors towards Internal Educational Quality Assurance of a University Course Tier. International Journal of Educational Management and Development Studies, Volume 2, Issue 1, pp. 1- 21.

\footnotetext{
About the authors:

${ }^{1}$ Corresponding author. Candidate for Master's Degree of Business Administration, Rajamangala University of Technology, Suvarnabhumi, Thailand

2Professor, Faculty of Business Administration and Information Technology, Rajamangala University of Technology, Suvarnabhumi, Thailand
} 


\section{Introduction}

Nowadays, the public and private sectors are in the midst of changing circumstances including social, economic, political, and technology. With high competition, organizations need to be more effective to cope with the changing situations in order to compete directly or indirectly with other organizations in the same fields. As such, each organization should also be able to deal and manage the impacts of these changing circumstances. It is expected that the management levels have to deploy a work system that will accomplish the strategies and tasks successfully according to the objectives and goals that are effectively set. For this, the management and personnel within the organization should be work hand in hand as an important factor and essential mechanism in driving the organization's management process successfully (Boonbongkarn \& Khajornnan, 2001).

The universities in Thailand are fully responsible for managing education system to produce quality graduates with an improved knowledge and understanding of their own specialized courses. In fact, students are learning both inside and outside the classrooms to improve critical thinking and solving problems from real-life situations. They are taught to be more creative with values such as morality and ethics to be their weapons and tools in their daily life as well as a being a dynamic member of the society. Truly, the role of colleges and universities are crucial in producing professionals in the future. For that reason, university administrators play a vital role in managing the course offerings. It requires management efficacy with application of an essential strategy to manage these courses. As it is required by most effective and successful organizations, the management of the university needs the leadership skills, knowledge, and capability in order to build an organization anchored on faith, cooperation, commitment, motivation, and confidence for the academic staff to cooperate and work together. This also creates methods and techniques within organizational management that enables them to lead an efficient organization (Chuchanad, 2018).

In the same context and perspective, the Rajamangala University of Technology heeds to the call of the changing landscape of higher education in Thailand. It is a public higher education institution under the supervision of the Ministry of Higher Education, Science, Research and Innovation of Thailand. The university is under control of the 
government division divided into ministerial regulations and internal government agencies and established by the University Council. The university is managed with five missions including producing graduates, research, providing academic service to society, preserving arts and culture of Thai tradition, and managing quality of management of educational institutions to continuously develop the quality of learners and to build confidence for educational service recipients (Rajamangala University of Technology, 2020).

According to the National Education Act 1999, No. 2 of Thailand 2002, educational institutions in the country must have an educational quality assurance system in order to produce fully qualified graduates with desirable characteristics. Therefore, operations and administration are most important, wherein there should be an internal educational quality assurance system for higher education (Office of the Higher Education, 2014). Rajamangala University of Technology has an educational quality assurance management that consists of 4 steps: Planning (Plan), Plan implementation (Do), Quality assessment (Check) and Revision (Action). These steps are consistent with the strategic management process, consisting of strategic planning, strategy implementation, and strategy control and evaluation.

From the given background and important concepts of this issue, this study examined the development of a causal model of factors affecting operational efficiency of the internal educational quality assurance for higher education at Rajamangala University of Technology. Specifically, it assessed the strategic management, transformational leadership, motivation, and operational efficiency of the internal quality assurance. It also tested the consistency of the causal model of factors affecting operational efficiency of internal educational quality assurance and the influence of strategic management, transformational leadership, and motivation on the internal educational quality assurance. This study expects that the results can be useful to the management of the university to increase the operational efficiency of its course management system. The results could also be useful for private and public educational institutions in their course management.

\section{Literature review}

\subsection{Educational quality assurance at Rajamangala University of Technology}


Based on the education reform concept, the focus on management decentralization to higher education institutions enables the public educational institutions to operate independently and to have flexibility in the management. Therefore, Rajamangala University of Technology Act was drafted to merge the nearby campuses and form nine (9) campuses of Rajamangala University of Technology covering all regions of the country. Rajamangala University of Technology is known as one of the largest educational institutions in Thailand entrusted with the full potential and capability to produce quality graduates. The university focuses on developing students to become a part of the global workforce to dominate the labor market in the country. The university maintains a mission to provide education based on science and technology with various majors and specializations that will send off graduates to serve the country.

The Office of the Higher Education Commission established a framework for developing an internal educational quality assurance system at the tertiary level. This is to maintain the quality of education the students get and the quality of graduates the educational institutions produced. The internal quality assurance system ensures that the institution adheres to the principles of quality. Through this, the institution has an internal mechanism to evaluate their courses and programs in order to meet the demands of the industry. In this regard, the relevant matters were considered in the framework of the 15-Year Higher Education Plan (2008-2022) including the 11th Higher Education Development Plan (20122016), Higher Education Standards, Higher Education Institution Standards of the Tertiary Curriculum Standards of 2005, and the 2009 National Qualifications Framework for Higher Education. The internal educational quality assurance was established including course level, faculty level, and institutional level with four missions of higher education institutions, and adding other essential aspects, as necessary. The current educational quality assurance system focuses on the course level.

The system, control, inspection, monitoring, assessment and development are the different aspects that have been implemented to ensure quality in the operations and managements of the institutions. These are also in place to promote, support, supervise and monitor the operations of the faculties and departments in accordance with the standards, policies and guidelines set by the higher education. The quality of the educational 
management reflects quality control in every step of producing graduates (Office of the Higher Education, 2014).

The Rajamangala University of Technology is categorized under the group 2, which is a higher education institution or an specialized institution for bachelor's degree (Rajamangala University of Technology, 2020). The university has guidelines for organizing the internal quality assurance process based on the quality cycle consisting of 4 steps: Planning (Plan), Plan implementation (Do), Quality assessment (Check) and Revision (Action).

\subsection{Strategic Management}

Strategic management directs any organization towards the achievement of its mission and vision. It is an important aspect that drives the entire organization. The elements of the strategic management process include strategic formulation, strategic implementation, and strategic control and evaluation (Chatriwisit et al., 2010). The management of the organization determines the vision, objectives, and the analysis of internal and external environment while taking into account the organizational context. The management also evaluates various factors affecting the change to plan operational process in which it enables to control the operations of the organizations efficiently.

One of the test of leadership in any academic institutions is the quality assurance and accreditation. According to Ritson (2011), academics classify three levels of strategies as corporate, competitive or business and operational. Leadership and management emanate from these levels. The corporate level intensifies the organizational leadership. The corporate leaders set the vision that requires a call for action. The governance, policy-making and major organization decisions are the major functions of this level. They lead the people and influence them to do their tasks to achieve their department objectives. However, their function does not end with setting the vision. They control the college resources through their decision-making power and delegation initiatives. On the other hand, the competitive level of the strategy focuses on the leadership and managerial functions. As leaders, they motivate their own subordinates to abide with the operational procedures and performance of duties 
with the utmost care. They also set departmental goals as targets for the academic year. Moreover, their biggest responsibility is keeping their own departmental jurisdiction in order through planning their targets and objectives, organizing the various resources, directing the staff to the proper process and procedures and controlling the work behaviors of the staff by setting corrective measures. Lastly, the operational level focuses more on effective management. These are the first line supervisors that direct and control the work performance of the staff. Their main function is to keep these people working according to plans. While they manage, they also lead to the efficacy of the job performance of a small group of people they line manage. Thus, in all these levels - effective leaders get the job done with staff support and effective managers achieve the goals through people.

The interdependence of strategic management and leadership can be highly emphasized in the educational institutions. As Marques (2013) quips, that strategic management in universities involves the multi-dimensional process of setting long-term goals based on the mission and vision that the leaders and collaborators define. In reality - strategic management sets the direction but leadership takes the people to aim in the right direction.

\subsection{Transformational Leadership}

Transformational leadership is fast becoming a trend in most of the educational institutions as a leaderships style focused on the behavior of the leader to develop the people. The transformational leadership theory was developed by Burns (1978) and was enhanced by Bass (1985) and Avolio \& Bass (1988). It was characterized as that which occurs when one or more persons engage with others in such a way that leaders and followers raise one another to higher levels of motivation and morality. Both the leader and follower learn from each other as they progress in their moral development in a selfless inspirational process. The major premise of the transformational leadership theory is the leader's ability to motivate the follower to accomplish more than what the follower planned to accomplish (Krishnan, 2005).

Transformational leadership is stimulating interests in work and co-workers. It creates awareness, vision, mission and loyalty. It always consider the interests of the organization rather than personal interests as a whole. Based on the theory of transformational leadership (Bass \& Avolio, 1994), the behavior components consists of idealized influence (II), 
inspirational motivation (IM), intellectual stimulation (IS), and individualized consideration (IC). Thus, the transformational leadership develops the ability of co-workers and followers to create higher abilities. In addition, Supprasert, P. (2018) claimed that the behavior can be observed by the people from the management skills of the leader. It is a process where leaders influence their co-workers to work effectively. It includes encouraging, transforming the efforts of colleagues, developing the ability of colleagues to have a higher potential and level within workplace (Supprasert, 2018). The transformational leaders then becomes an ideological influencer, an inspirer, a motivator, and a considerate individual (Arunno, 2016).

\subsection{Motivation}

Motivation is the internal and external factors that motivates or drives individuals in an organization to cooperate with each other. The theoretical motive elements of Herzberg, Mausner, \& Snyderman (1959) consists of success in work (achievement), nature of the work (work itself), responsibility in the work (responsibility), to be respected (recognition), and advancement in the position (advancement). Motivation creates incentives for personnel to perform the work and builds operational efficiency (Ariyaphatmongkol, 2017; Charin, 2015). Thus, the motivation enables the organization to achieve the set goals effectively.

\subsection{Operational Efficiency}

Operational efficiency refers to the operation that meets cost-effective expectations from the use of resources, quality, reliability, timeliness, performance and quality standards. Firms that meet the operational efficiency focus on providing products or services to satisfy customers' needs and expectations (Khamma, 2018; Kajornnam, 2017).

The operational efficiency of the internal educational quality assurance operation course of Rajamangala University of Technology refers to the lecturers in-charge of the course who have knowledge, ability, and qualifications to operate the quality assurance for higher education successfully and efficiently. The measurement of the operational performance is based on the course standards. Operation is in accordance with the tertiary qualification standard framework. The framework is implemented with the educational quality assurance process according to the time-frame set by the university. 
From the concepts and literature discussed, the research conceptual framework was designed.

\section{Figure 1}

Research conceptual framework

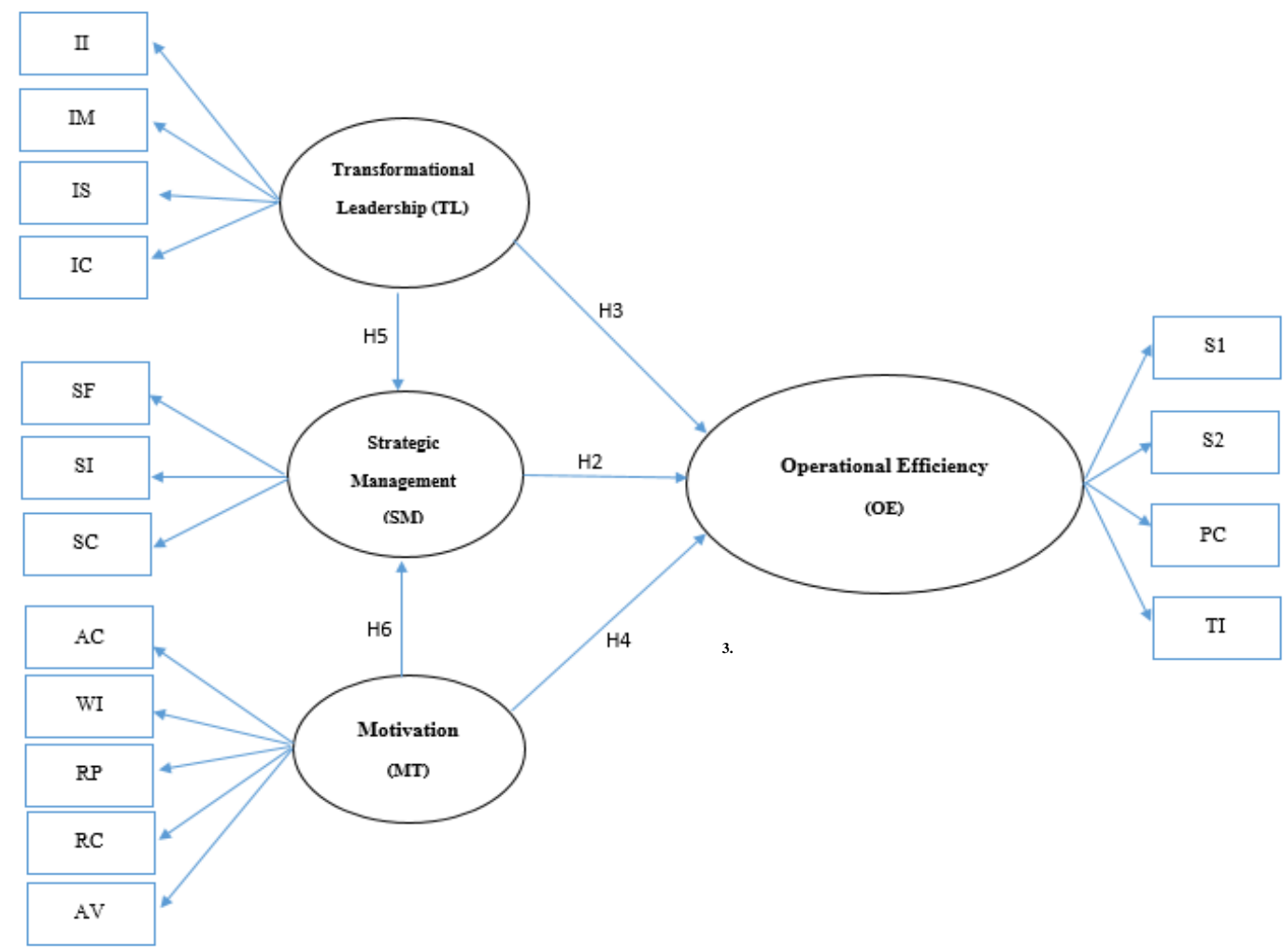

The framework consists of the three main variables affecting the operational efficiency as transformational leadership, strategic management and motivation. These three main variable have different sub-variables termed as factors that will be tested to determine its effect on the operation efficiency. Taking the relationships as shown in Figure 1, the following eight hypotheses were formulated:

H1: A causal model of factors has an effect on operational efficiency of internal quality assurance for higher education.

H2: Strategic management has a positive direct influence on operational efficiency, quality assurance, and internal education for higher education.

H3: Transformational leadership has a positive direct influence on the operational efficiency of internal educational quality assurance for higher education. 
H4: Motivation has a positive direct influence on operational efficiency of internal educational quality assurance for higher education.

H5: Transformational leadership has a positive direct influence on strategic management.

H6: Motivation has a positive direct influence on strategic management.

H7: Transformational leadership influences strategic management and affects operational efficiency of the quality assurance for higher education.

H8: Motivation influences strategic management, quality assurance operational performance and internal educational quality assurance for higher education.

\section{Methodology}

\subsection{Research design}

This study employed quantitative research methods to develop a causal model of factors affecting the operational efficiency of internal educational quality assurance for higher education at Rajamangala University of Technology. A set of questionnaires was designed to collect data from the 236 samples.

\subsection{Sample size and selection}

The sample group in this study was a representative of the lecturers who were the course leaders of the nine campuses at Rajamangala University of Technology in Thailand. An automated program was used to calculate the sample size. The influence (effect size) was 0.3 and the power of the test was 0.80 , with a significance level of 0.05 and confidence equal to 0.95 . The number of observable variables was 16 , the latent variable was 4 , and the sample size was 137 lecturers. The sample size was large enough for the estimated parameter to be constant and valid. In order to expand the sample, the calculated number of respondents was increased during an additional period of data collection from 17- 30 November 2020. At the end of the data collection, a total of 236 lecturers agreed to participate in the study. Overall, 236 lecturer-participants were selected from the nine campuses of the Rajamangala University of Technology in Thailand using purposive sampling methods. These lecturers 
were the course leaders of the programs from each campus who were purposively chosen for investigations.

\subsection{Research instrument}

A self-made questionnaire was designed as the main data gathering tool. It was answerable using a 5-scale Likert style. It contains four sections. The first section consists of the assessment of the strategic management and the internal management practices of the nine campuses of the university. The second section contains questions relevant to the operational efficiency of the internal quality assurance of the nine campuses. The third section was about the transformational leadership including employee turnover and organizational engagement. The last section was related to the motivation in relation to the management effectiveness, goals and objectives of the university.

\subsection{Data collection}

The study collected primary data through a self-made questionnaire. In order to gather data and consider the research ethics at the same time, the author followed the following process:

1. An official letter was sent to the Rajamangala University of Technology, Suvarnabhumi campus to obtain approval from the Director of the Office of Educational Quality Assurance in the conduct of the research from the nine (9) campuses. Quick Respond or QR Code was used to collect data through online questionnaire.

2. The questionnaires were retrieved and collected soon after respondents completed all the sections. Upon receiving the online response form, it was checked for accuracy and completeness.

3. After the collection of online questionnaire forms from all the lecturerrespondents, the answers were coded, entered and recorded for computer analysis. The data were processed and recorded for further statistical analysis. 


\subsection{Data analysis}

This study employed descriptive statistics using frequency and percentage to analyse the general data from the respondents. The mean and standard deviation were used to analyse the respondents' assessment of the strategic management, transformational leadership, motivation, and operational efficiency. The construct validity analysis method was used to examine the consistency of the factors affecting the effectiveness of the internal educational quality assurance at the curriculum level with empirical data. The path analysis statistics were utilized to test the influence paths based on causal models between variables including direct influence, indirect influence, and the total influence (parameter estimation from the model) and verification of the conformity of the model (goodness of fit measures) (Wiratchai, 1999).

\section{Findings and Discussion}

\subsection{Research findings}

\section{Table 1}

The efficiency of the course management at Rajamangala University of Technology

\begin{tabular}{lccc}
\hline \multicolumn{1}{c}{ Factors } & $\overline{\mathrm{X}}$ & S.D. & Interpretation \\
\hline 1. Strategic management & 4.10 & 0.64 & Highly Effective \\
2. Transformational leadership & 4.06 & 0.69 & Effective \\
3. Motivation & 4.19 & 0.66 & Highly Effective \\
4. Operational efficiency of internal quality assurance & $4 . .30$ & 0.62 & Highly Effective \\
\hline
\end{tabular}

The table 1 shows the means and standard deviation on the assessment of the course management at Rajamangal University of Technology. The lecturer-respondents assessed through the variables strategic management, transformational leadership, motivation and internal quality assurance.

The results revealed that overall, the operational efficiency of internal quality assurance was at $4.30(\mathrm{SD}=0.62)$, followed by motivation $(4.19, \mathrm{SD}=0.66)$, strategic management (4.10, S.D. = 0.64), and transformational leadership (4.06, S.D. = 0.69). It shows that the strategic management, motivation and operational efficiency of the internal quality assurance are highly effective while transformational leadership is effective. 
Table 2

Analysis of causal models, influence of internal and external latent variables

\begin{tabular}{|c|c|c|c|}
\hline Path Diagram & Path Coefficients & Standard Errors & t-values \\
\hline \multicolumn{4}{|l|}{ GAMMA } \\
\hline $\mathrm{TL} \rightarrow \mathrm{OE}$ & -.033 & .024 & 1.42 \\
\hline $\mathrm{TL} \rightarrow \mathrm{SM}$ & $.069 * *$ & .011 & 6.49 \\
\hline $\mathrm{MT} \rightarrow \mathrm{OE}$ & $.062 * *$ & .011 & 5.75 \\
\hline $\mathrm{MT} \rightarrow \mathrm{SM}$ & $.020 *$ & .010 & 2.01 \\
\hline \multicolumn{4}{|l|}{ BETA } \\
\hline $\mathrm{SM} \rightarrow \mathrm{OE}$ & $.061 *$ & .031 & 1.97 \\
\hline $\begin{array}{l}\text { Note: Path Diagr } \\
\text { * Statistical signi } \\
* * \text { Statistical sigr }\end{array}$ & $\begin{array}{l}\text { Path Coefficients we } \\
.960 \leq t-\text { value }<2.5 \\
\text { value } \geq 2.576) \text {. }\end{array}$ & oefficients. & \\
\hline
\end{tabular}

The table 2 shows the analysis of the causal models and the influence of the internal and external latent variables. It depicts the hypothesized relation tested in an analysis of simultaneous linear relationships. It reflects the causal relations of the variables.

The results show that the conceptual framework analysis (hypothesized model) was adjusted by allowing discrepancies to relate and correspond in meeting the reality. The study then adjusted the model to align the conceptual framework with the empirical data. As a result, the structural equation model after adjustment was consistent with the empirical data. The hypotheses were consistent with the empirical data. The study considered the statistics and found that the chi-square statistic ) $\chi 2$ ) was 82.11 and degrees of freedom (df) was 64, significantly different from zero ( $\mathrm{p}$-value $=0.06325$ ), according to the standard must be greater than 05 . The relative chi-square value ) $\chi 2 / \mathrm{df}$ ) was 1.28 (the standard should not exceed 2). Value from 0.9 and above, AGFI value was 0.96 (standard should be a value from 0.9 and above), RMSEA value was 0.024 (standard should be less than 0.05), as shown in Table 2 and Figure 2.

This study further made a comparison of model consistency statistics with empirical data between hypothesized models and modified model. The analysis of the comparison between the two models showed that the preliminary agreement of statistical analysis with a package allowed the error variance to be related after adjusting (Wiratchai, 1999). It resulted to a newly adjusted model consistent with the empirical data. 


\section{Figure 2}

The adjusted causal model

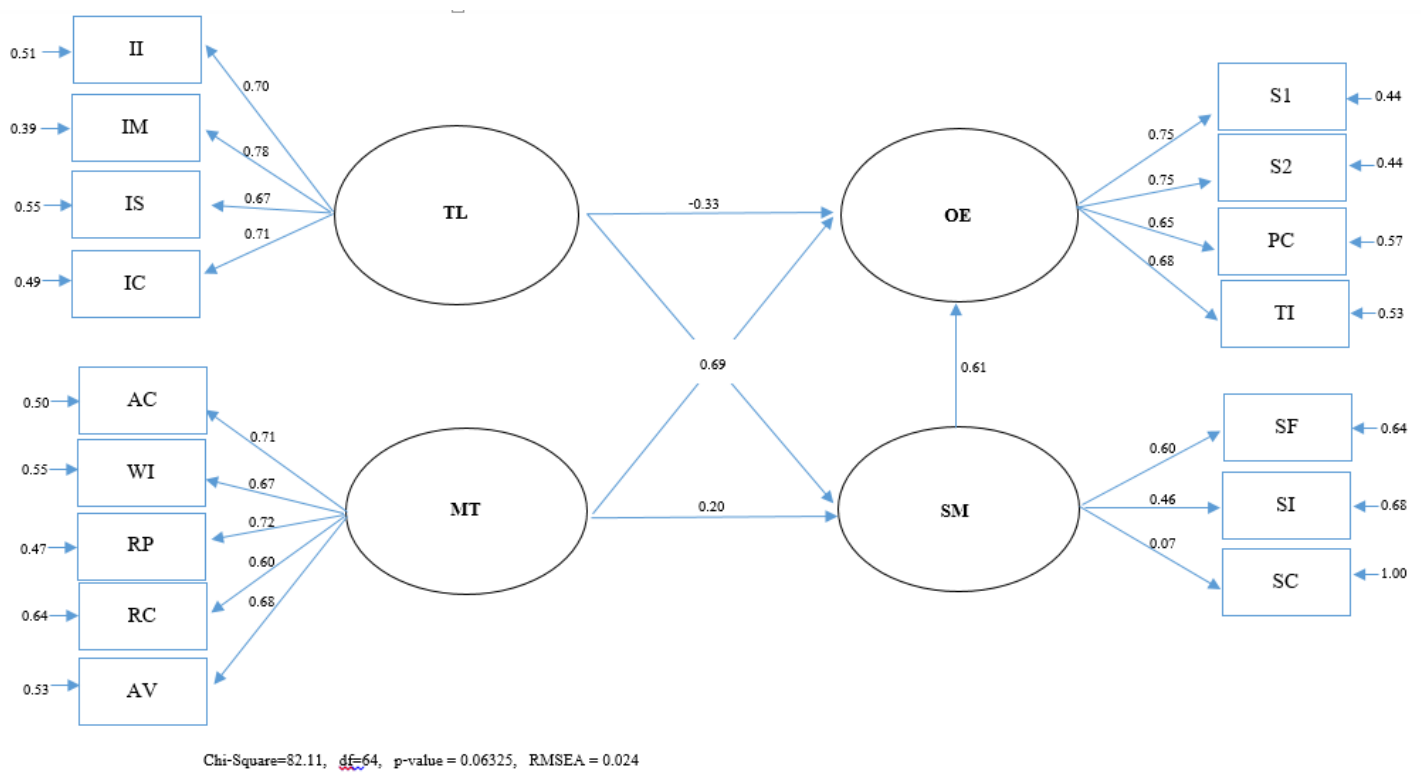

Table 3 shows the direct and indirect influence combined with influence of strategic management, tranformational leadership and motivation influencing operational efficiency of the internal quality assurance of the university.

\section{Table 3}

The direct and indirect influence of the different variables

\section{Internal latent variables}

\begin{tabular}{|c|c|c|c|c|c|c|c|}
\hline \multirow[t]{2}{*}{ Influencing factors } & & \multicolumn{3}{|c|}{ Strategic management $)$ SM( } & \multicolumn{3}{|c|}{ Operational efficiency )OE( } \\
\hline & & TE & DE & IE & TE & $\mathbf{D E}$ & IE \\
\hline \multirow{2}{*}{$\begin{array}{l}\text { Strategic } \\
\text { management }) \mathrm{SM}(\end{array}$} & $\beta$ & - & - & - & $0.61 *$ & $0.61 *$ & - \\
\hline & SE & - & - & - & $(0.31)$ & $(0.31)$ & - \\
\hline \multirow{2}{*}{$\begin{array}{l}\text { Transformational } \\
\text { leadership } \\
\text { )TL( }\end{array}$} & $\Gamma$ & $0.69 * *$ & $0.69 * *$ & - & 0.09 & -0.33 & 0.42 \\
\hline & SE & $(0.11)$ & $(0.11)$ & - & $(0.07)$ & $(0.24)$ & $(0.23)$ \\
\hline \multirow{2}{*}{ Motivation)MT( } & $\Gamma$ & $0.20^{*}$ & $0.20 *$ & - & $0.75^{* *}$ & $0.62 * *$ & 0.13 \\
\hline & SE & $(0.10)$ & $(0.10)$ & - & $(0.08)$ & (011) & $(0.08)$ \\
\hline
\end{tabular}


Table 3 shows that the factors influencing the two internal latent variables were strategic management affecting operational efficiency of internal quality assurance. The Operational efficiency (OE) of internal quality assurance for higher education at Rajamangala University of Technology was most influenced by Motivation (MT), with a positive total influence of 0.75 and statistically significant at the scale of 0.01 . There was a positive direct influence of 0.62 at level 0.01 with a positive indirect influence of 0.13 which it was not statistically significant. Strategic management (SM) had a positive total influence of 0.61 , with a statistically significant influence at 0.05 . The positive direct influence was 0.61 which it was statistically significant at the 0.05 level. The transformational leadership (TL) had a statistically significant positive influence of 0.09 , the negative direct influence of -0.33 and the the positive indirect influence was 0.42 , which was not statistically significant. Strategic management (SM) was combined with influence of transformational leadership (TL). It was the highest level with a positive influence of 0.69 and statistically significant at the 0.01 level. A positive direct of influence was 0.69 and statistically significant at the 0.01 level, followed by motivation (MT) with a positive total influence of 0.20 statistically significant at the 0.05 level, and a positive direct influence of 0.20 statistically significant at 0.05 level.

\subsection{Discussion}

Based from the result, the conceptual framework built on the assumption (hypothesized model) was inconsistent with the empirical data. The study modified a conceptual model according to the discrepancies which it needed to be related. After modificaton of the conceptual model, the structural equation was consistent with the empirical data showing that the H1 hypothesis was accepted for two reasons. First, the study developed structural equation model from theory, concepts, previous research with content-

oriented and structural validity. In each model, the measurements were obtained through the synthesis of the main components. Sub-elements, definitions, terms and indicators were derived from the concepts, theories and review of the previous studies. In all measurement models, statistical values passed the specified criteria. There was reliability of the latent variable which they were predictive coefficients of structural equations of all measurement models greater than the specified criteria. This study designed the conceptual model analysis 
based on Joreskog's analysis of Structural Equation Model (SEM) developed in 1960 (Wiratchai, 2005). Second, the opinions on the operational effeciency of internal educational quality assurance at Rajamangala University of Technology showed that the overall sample group was at the highest level (4.30). The implementation of the higher education internal quality assurance was related to the implementation of tertiary course standards based on the National Qualifications Framework for Higher Education. The implementation was following the plan, do, check and action (PDCA) process and based on the time frame set by the university. This was consistent with the study of Kittiwimonchai et al., (2008) that the quality assurance had a positive impact. Although the process was tricky and complex, it had to be performed continuously. And quality assurance was a wide range of improvements in quality and productivity. Staff were involved and working as a team. The university encouraged staff to know their duties, join in the operational planning and systematically collect all pertinent information. There was a comparison of performance, development of weakest point, assessment culture, good image, reputation, and credibility, as a whole.

The results affirmed $\mathrm{H} 2$ that the strategic management had a positive direct influence on the operational efficiency of internal quality assurance for higher education at Rajamangala University of Technology. Strategic management, as an administrative process, leads to the success of the university. The results were consistent with the study of Sathienkong (2014), which identified that ten government departments of Thailand with a similar pattern for setting goals and operational strategies emanating from the analysis of the internal and external environment as fundamental information. These management strategies were implemented with the ten departments through communicating, adjusting, and opening minds to the changes with the authorities of the ten departments. All parties from all levels were involved in the development of quality and creation of strategies emphasizing on continuous investigation, evaluation, and correction in order to meet the goals of each department.

In addition, the transformational leadership had a negative direct influence on the operational efficiency of the internal educational quality assurance implementation for higher education at Rajamangala University of Technology. Thus, the H3 was rejected. The results were consistent with the study of Mekto (2017) that transformational leadership was 
positively correlated with organizational engagement, negative correlation with employee turnover, and negative relationship with organizational engagement. The intention was to reduce high number of leaving employees. The results also indicated that the employees perceived the importance of the transformational leadership in the university. However, the institution should provide development programs for leaders at all levels for the actualization of the transformational leadership. This is to strengthen the organizational engagement and reduce employee turnover. Moreover, the study of Amankwaa and Anku-Tsede (2015) as cited in Mekto (2017) found that employees with a high level of transformational leadership awareness had lower employee turnover than those employees with lower awareness. In addition, Saengklaharn (2016) through the transformative perception of leadership quality of work life, perception, justice within organization, and occupational stress, found that transformational leadership perceptions were significantly associated with work stress at a level of 0.01 with a correlation coefficient equal to -.497 .

The results also answered $\mathrm{H} 4$ that motivation had a positive direct influence on the operational efficiency of the internal quality assurance implementation for higher education at Rajamangala University of Technology. The motivation was a key factor driving individuals within institutions to cooperate willingly with each other to effectively achieve the goals. The results were consistent with the study of Charin (2015) that the motivation factors affected the performance of staff of the Cooperative Office in Khon Kaen Province. The employee motivation focused on successful policy and administration acceptance, characteristic of work, and job responsibility were correlated with job performance. Meanwhile, the motivation related to career advancement including salary and benefits, and job security were associated with coherent performance at low level and the motivations related to working conditions were associated with coherence with efficiency at very low level.

Furthermore, H5 was also affirmed that the transformational leadership has a positive direct influence on strategic management. The results supported the presumptions that successful and effective operations were achieved if the organization had transformational leadership. This is consistent with the study of Worakanthiwat (2012) on the role of the strategic leadership of private vocational school administrators in Bangkok based on the perception of administrators and teachers. Similarly, the strategic leadership of the private 
vocational school administrators in Bangkok based on the perception of administrators and teachers was highly effective.

With regards to $\mathrm{H} 6$, the results confirmed that motivation had a positive direct influence on strategic management. Motivation was one of the key factors within the institution that support management effectiveness. This was consistent with the study of Moosik (2018) which studied the strategic management of hospitals under the Ministry of Public Health. Similarly, motivation makes personnel to be enthusiastic in implementing the ward's annual operating plan. The long-term strategic plan was achieved through the consensus and concerted efforts of the motivated personnel. Through the motivation, they have the strong intention and enthusiasm to perform their individual contribution to the objectives of the organization. The implementation of the annual performance plan including motivation strategies was essential to any organization to achieve their short and long-term goals. However, the study rejected H7: Transformational leadership influences strategic management and affects operational efficiency of the quality assurance for higher education and H8: Motivation influences strategic management, quality assurance operational performance and internal educational quality assurance for higher education. The transformational leadership has no clear indication of influence to the strategic management and operational efficiency of the quality assurance. This indicates that a specific type of coaching and mentoring through transformational leadership cannot guarantee that the strategic management can be accomplished to sustain the operational efficiency. For this, the concerted efforts of all management levels and departments are needed.

\section{Conclusion}

This study examined the development of a causal model of factors affecting operational efficiency of the internal educational quality assurance for higher education at Rajamangala University of Technology. Specifically, it assessed the strategic management, transformational leadership, motivation, and operational efficiency of the internal quality assurance. It also tested the consistency of the causal model of factors affecting operational efficiency of internal educational quality assurance and the influence of strategic management, transformational leadership, and motivation on the internal educational quality 
assurance. Through the quantitative research methods, 236 lecturer-respondents were purposively chosen from the nine campuses of the university. Data gathered using a selfmade questionnaire was treated using descriptive and inferential statistics.

The results proved the six hypotheses as correct thereby accepting the null whereas the two hypotheses were rejected. It confirmed that the causal model of factors has an effect on operational efficiency of internal quality assurance for higher education; the strategic management has a positive direct influence on operational efficiency, quality assurance, and internal education for higher education; the transformational leadership has a positive direct influence on the operational efficiency of internal educational quality assurance for higher education; motivation has a positive direct influence on operational efficiency of internal educational quality assurance for higher education; transformational leadership has a positive direct influence on strategic management and motivation has a positive direct influence on strategic management. The results further proved that transformational leadership has no influence on strategic management and has no effects on operational efficiency of the quality assurance for higher education. Similarly, motivation has no influence on strategic management, quality assurance operational performance and internal educational quality assurance for higher education. It is clear from the results that strategic management, transformational leadership, motivation and operational efficiency of the internal quality assurance have inter-connected relationship that highly affects the organizational performance of the university.

The results of the study are beneficial to the university and other colleges and universities in and outside the country. These are fundamental to the planning and development of the strategies in order to improve the operational efficiency and internal quality assurance of the programs. As the role of the higher education is getting crucial, the internal quality assurance keeps the quality of the programs up-to-date and relevant to the needs of the community and the industry. With the stiff competition in higher education, colleges and universities must keep the quality of their graduates their utmost responsibility.

The study is very specific to one university in Thailand that limits the comparative analysis and wider grasp of the variables in different nature of the organization. Moreover, the data gathered were limited to quantitative, which also limit the in-depth characterization 
of the variables specifically the strategic management and internal quality assurance practices. With these limitations, further studies are encouraged. Researchers can use an indepth interview and choose other colleges and universities for comparative analysis. Further research an also focus on the investigation of the various factors affecting operational efficiency of internal educational quality assurance for higher education in Thailand.

\section{Acknowledgement}

The first author is thankful to the Master's thesis advisor, Assistant professor Dr. Seni Puangyanee. With his great kindness and support, the study was completed successfully. His advice were very helpful in conducting the study and producing the research output for international journal publication. Gratitude is also extended to the teachers of Rajamangala University of Technology for their support, guidance and knowledge shared during the completion of the MBA program.

\section{References}

Amankwaa, A., \& Anku-Tsede, O. (2015). Linking Transformational Leadership to Employee Turnover: The Moderating Role of Alternative Job Opportunity. International Journal of Business Administration, 6(4), 19-29.

Arayaphatmongkol, S. (2017) The Study of Relationship Between Work Motivation and Internal Quality Assurance Operations of Teachers (Master of Education), Phranakhon Si Ayutthaya Rajabhat University.

Aroonno, N. (2016). A study of transformational leadership among school administrators affecting the effectiveness of educational institutions under the office of the secondary educational service - area 17. (Master of Science in Educational Administration), Rambhaibarni Rajabhat University.

Avolio, B. J., \& Bass, B. M. (1988). Transformational leadership, charisma, and beyond. In J. G. Hunt, B. R. Baliga, H. P. Dachler, \& C. A. Schriesheim (Eds.), International leadership symposia series. Emerging leadership vistas (p. 29-49). Lexington Books/D. C. Heath and Com. 
Bass, B. M., \& Avolio, B. J. (1994). Improving organization effectiveness throught transformational leadership. Thousand Oaks: Sage.

Bass, B.M. (1985). Leadership and performance beyond expectations. New York: The Free Press.

Boonbongkarn, J., \& Khajornnan, N. (2001). Strategic management. Se-Education: Bangkok. Burns, J.M. (1978). Leadership. New York: Harper \& Row.

Charin, A. (2015). Motivation factors affecting the performance of personnel. Cooperative Office Khon Kaen Province. (Master of Business Administration), Sukhothai Thammathirat Open University.

Chatriwisit, R., Phuchinda, K., Chutrakul, A., Chinanurak, N., Puengkrai, P., \& Nilju, W. (2010). Strategic Management: Strategic Management. Bangkok: Tangsap Printing.

Chuchanad, D. (2018). Strategic Management of Mahachulalongkornrajavidyalaya University. (Doctor of Philosophy ), University of North Bangkok.

Herzberg, F., Mausner, B., \& Snyderman, B. (1959). The Motivation of Work. New York John Wiley \& Sons.

Kajornnam, A. (2017). The Impact of Innovative Knowledge on the Performance of Accountants in the Northeastern Region. (Master of Accounting) Mahasarakham University.

Khamma, P. (2018). Relationship between Professional Accounting Competency Development and Performance of Finance and Accounting Scholars. Rajamangala University of Technology Isan. (Master of Accounting), Faculty of Accountancy and Management, Mahasarakham University.

Kittiwimonchai, P., Phanchaipet, K., Sonthipreem, S., Panneesakthatsana, \& Phonpaisan, P. (2008). Efficiency and effectiveness of quality assurance. Khon Kaen University. Khon Kaen: Khon Kaen University.

Marques, M.C.C. (2013). Strategic management, leadership and governance of university in Portugal. Munich Personal RePEc Archive. MPRA Paper No. 53017.

Mekto, B. (2017). Influence of transformational leadership on organizational engagement and employee resignation intention: a case study of a packaging material manufacturing company. HROD JOURNAL, 9(1), 36-59. 
Moosik, S. (2018). Strategic Management of Wards for Tertiary Hospital Under the Ministry of Public Health. (Doctor of Philosophy ), Christian University.

Office of the Higher Education. (2014). Commission Internal Quality Assurance Manual Higher Education Bangkok: Prints.

Rajamangala University of Technology. (2020). The Free Encyclopedia.

Ritson, N. (2011). Strategic management. London: Neil Ritson \& Ventus Publishing ApS

Saengklaharn, W. (2016). Perceptions of transformational leadership Quality of work life, perception, justice in the organization And work stress: a case study of employees in an independent organization. (Master of Arts), Thammasat University.

Sathienkong, J. (2014). Strategies for Success in Public Management in Thailand. (Doctor of Philosophy), Burapha University.

Supprasert, P. (2018). Leadership, Change that Affects the Performance of Red Scene Company Employees. (Master of Education), Ramkhamhaeng University.

Wiratchai, N. (1999). Statistical analysis model for research. Bangkok: Chulalongkorn University Press.

Wiratchai, N. (2005). Statistics to use Bangkok: Chulalongkorn University: Press.

Worakanthiwat, P. (2012). Strategic leadership of private vocational school administrators Bangkok According to the perception of administrators and teachers. (Master of Education ), Graduate School, Dhurakij Pundit University. 